\title{
Arsenic content, fractionation, and ecological risk in the surface sediments of lake
}

\author{
S. L. Wang $\cdot$ C. Y. Lin $\cdot$ X. Z. Cao \\ X. Zhong
}

Received: 17 July 2010/Revised: 9 March 2011/Accepted: 7 August 2011/Published online: 24 November 2011

(c) CEERS, IAU 2011

\begin{abstract}
The Nansi Lake has been seriously affected by long-term intensive industrial and urban activities. The objectives of this study were to determine the content, distribution, and ecological risk of arsenic and investigate the geochemical relationships between arsenic forms and sediment mineral phases of the Nansi Lake. Twenty samples of surface sediments were collected and analyzed for arsenic contents and chemical forms. Results indicated that total content of arsenic in the sediment samples averaged $13.45 \mathrm{mg} / \mathrm{kg}$ and ranged from 8.27 to $21.75 \mathrm{mg} / \mathrm{kg}$. The arsenic was mostly associated with iron oxides $(67.3 \%)$, followed by the association with the residual fraction (19.2\%). In addition, total content of arsenic was positively correlated with the organic matter and iron contents in the sediment. The molar ratios of iron oxide bound arsenic content to iron content are lower than the maximal molar ratios of arsenic to iron for natural hematite, magnetite, and goethite. The total content of arsenic in the sediment samples was usually higher than threshold effect concentration of $9.79 \mathrm{mg} / \mathrm{kg}$, but lower than probable effect concentration
\end{abstract}

S. L. Wang · C. Y. Lin ( $ه)$

State Key Laboratory of Water Environment Simulation,

School of Environment, Beijing Normal University,

Beijing 100875, People's Republic of China

e-mail: c.lin@bnu.edu.cn

X. Z. Cao

School of Geography and Tourism, Qufu Normal University, Qufu 273165, People's Republic of China

X. Zhong

School of Life Science, Qufu Normal University,

Qufu 273165, People's Republic of China of $33.0 \mathrm{mg} / \mathrm{kg}$ for arsenic in freshwater sediments. Adverse effects or toxicity to the aquatic organisms, caused by arsenic in the sediments of the Nansi Lake, will likely occur at these levels of arsenic contamination.

Keywords Assessment - Chemical partitioning . Distribution · Effluence · Geochemistry

\section{Introduction}

Arsenic is widely recognized as one of the most toxic chemical elements and is also considered to be the prime naturally occurring carcinogen in the environment. Thus, arsenic pollution in natural environment has become a widely concerned problem all over the world (Smedley and Kinniburgh 2002). Anthropogenic sources for arsenic generally include metal mining and smelting, coal burning, waste incineration, industrial and municipal wastewater, and pesticides etc. (Chilvers and Peterson 1987). The average content of arsenic is $5.0 \mathrm{mg} / \mathrm{kg}$ in world river sediments (Martin and Whitfield 1983), while the content in the uppermost contaminated sediments of the Wells $\mathrm{G} \&$ $\mathrm{H}$ wetland can be as high as $15,000 \mathrm{mg} / \mathrm{kg}$ (Blute et al. 2009). Arsenic in sediments may produce adverse effects on aquatic organism, water column quality, and human health via food chain. Therefore, arsenic contamination in sediments has become a hot area of research.

In general, bioavailability, toxicity, and mobility of heavy metals including arsenic in sediments are largely influenced by its speciation (Wenzel et al. 2001; Karbassi et al. 2006; Feng et al. 2009). Sequential chemical extractions have the advantage of sufficient sensitivity to quantify $\mathrm{mg} / \mathrm{kg}$ concentrations of arsenic and apportion the arsenic into pools based on chemical properties of the 
target binding phases (Keon et al. 2001). Thus, sequential selective extraction procedures have been used to reveal the distribution information of As in sediments (Gruebel et al. 1988; Wenzel et al. 2001), though extraction schemes have sometimes some disadvantages, such as operation character, lack of selectivity of the reagents used, lack of quality control, and the dependence of the results on the procedure chosen (Filgueiras et al. 2002). The determination of the arsenic species is important for accurate assessments of environmental impact and human health risk.

The Nansi Lake $\left(34^{\circ} 27^{\prime}-35^{\circ} 20^{\prime} \mathrm{N}, 116^{\circ} 34^{\prime}-117^{\circ} 21^{\prime} \mathrm{E}\right)$ is a typical shallow lake with an area of $1,266 \mathrm{~km}^{2}$ and average depth of $1.46 \mathrm{~m}$, including four lakes: the Nanyang Lake, the Dushan Lake, the Zhaoyang Lake, and the Weishan Lake. It is the largest freshwater lake in the southwest of Shandong province and become one of the largest buffering reservoirs in the East Route of China's South-North Water Transfer Project. After the building of a dam in 1960s, Nansi Lake was divided into two parts: the upper lake and lower lake. The upper lake including the Nanyang Lake, the Dushan Lake, and the Zhaoyang Lake drains an area of more than $1,000 \mathrm{~km}^{2}$. The lower lake referring to the Weishan Lake drains an area of more than $200 \mathrm{~km}^{2}$

The urban streams are often contaminated by effluents and other wastes from industrial and domestic sources (Phiri et al. 2005; Mohiuddin et al. 2010; Sekabira et al. 2010). There has been a rapid economic development in the region around the Nansi Lake since 1970s and this rapid industrialization and urbanization might lead to an excessive release of pollutants into the Nansi Lake. Generally, the untreated effluents from industrial and municipal activities, the runoff from mining sites and agricultural land, and the deposition of air pollutants all contribute to the increase of heavy metal levels in the sediments. According to the "Water pollution Prevention Planning of the South-to-North Water Diversion Project (east route) of Shandong Section", water quality of the lake should be better than the Grade III of the "China surface water quality standard". However, previous researches indicated that the sediments of the Nansi Lake and its main inflow rivers were polluted by heavy metals (Liu et al. 2007). Previous research only sporadically focused on the total content of Arsenic (As) in the sediments (Liu et al. 2007) and no literature reports the chemical forms of As in the sediments of the Nansi Lake.

Therefore, the major objectives of this study were to characterize the contamination, chemical forms, and ecological risk of As in the surface sediments of the Nansi Lake and investigate geochemical relationships between As forms and sediment mineral phases.

\section{Materials and methods}

Sediment sampling

In this study, 20 samples of surface sediment were collected (Fig. 1) from 0 to $10 \mathrm{~cm}$ depth in May 2008 (seven samples in the Nanyang Lake, six samples in the Dushan Lake, four samples in the Zhaoyang Lake, and three samples in the Weishan Lake) using cable operated sediment samplers (Van Veen grabs, Eijkelkamp). Then, the samples were placed in dark-colored polyethylene bags and taken to the laboratory immediately after collection. All sediment samples were freeze-dried (FD-1A, China), slightly crushed, passed through a $2 \mathrm{~mm}$ sieve, and stored at $4^{\circ} \mathrm{C}$ in glass bottles before analysis.

Analytical methods

\section{General properties}

The $\mathrm{pH}$ value of the sediment samples was measured in a 1:10 solid:liquid ratio suspension using a combination $\mathrm{pH}$ electrode (Orion, USA). The amount of sediment organic matter (OM) was determined by the potassium dichromate dilution heat colorimetric method (Bao 1999). The grain size distribution of the sediment samples was analyzed using a Mastersizer 2000 Laser Size Analyzer (Malvern Co., UK) and the percentages of clay $(<2 \mu \mathrm{m})$, silt $(2-63 \mu \mathrm{m})$, and sand fractions $(63-2,000 \mu \mathrm{m})$ were calculated. Another aliquot of sediment sample was digested with $\mathrm{HNO}_{3}-\mathrm{HF}-\mathrm{HClO}_{4}$ and the concentrations of $\mathrm{Al}, \mathrm{Fe}$, and $\mathrm{Ca}$ in the supernatant were measured by ICP-AES (IRIS Intrepid II, Thermo Electron Co., USA).

The accuracy of the total $\mathrm{Al}, \mathrm{Fe}$, and Ca measurements was checked by conducting an analysis of three reference materials (GSS1, GSS2, GSS9) from Institute of Geophysical and Geochemical Exploration, Chinese Academy of Geological Science. The average relative errors of $\mathrm{Al}$, $\mathrm{Fe}$, and $\mathrm{Ca}$ measurements in the three reference materials were -1.47 to $2.89,-0.10$ to 2.78 , and 1.35 to $2.24 \%$, respectively. The precision was evaluated by the variation of coefficients (CV) of two replicates from four sediment samples. Average CVs were 2.35, 2.02, and $1.64 \%$ for $\mathrm{Al}$, $\mathrm{Fe}$, and $\mathrm{Ca}$, respectively.

Total As and sequential extraction analysis of As

Another aliquot of sediment sample was digested with aqua regia $\left(1 \% \mathrm{KMnO}_{4}\right)$ and $1 \%$ oxalic acid. The As concentration in the supernatant was measured by hydride generation-atomic fluorescence spectroscopy (HG-AFS) (HG-AFS230, Beijing Haiguang Instruments, Inc., China). The accuracy of the total As (TAs) measurements was 
Fig. 1 Location map of sampling sites in the Nansi Lake

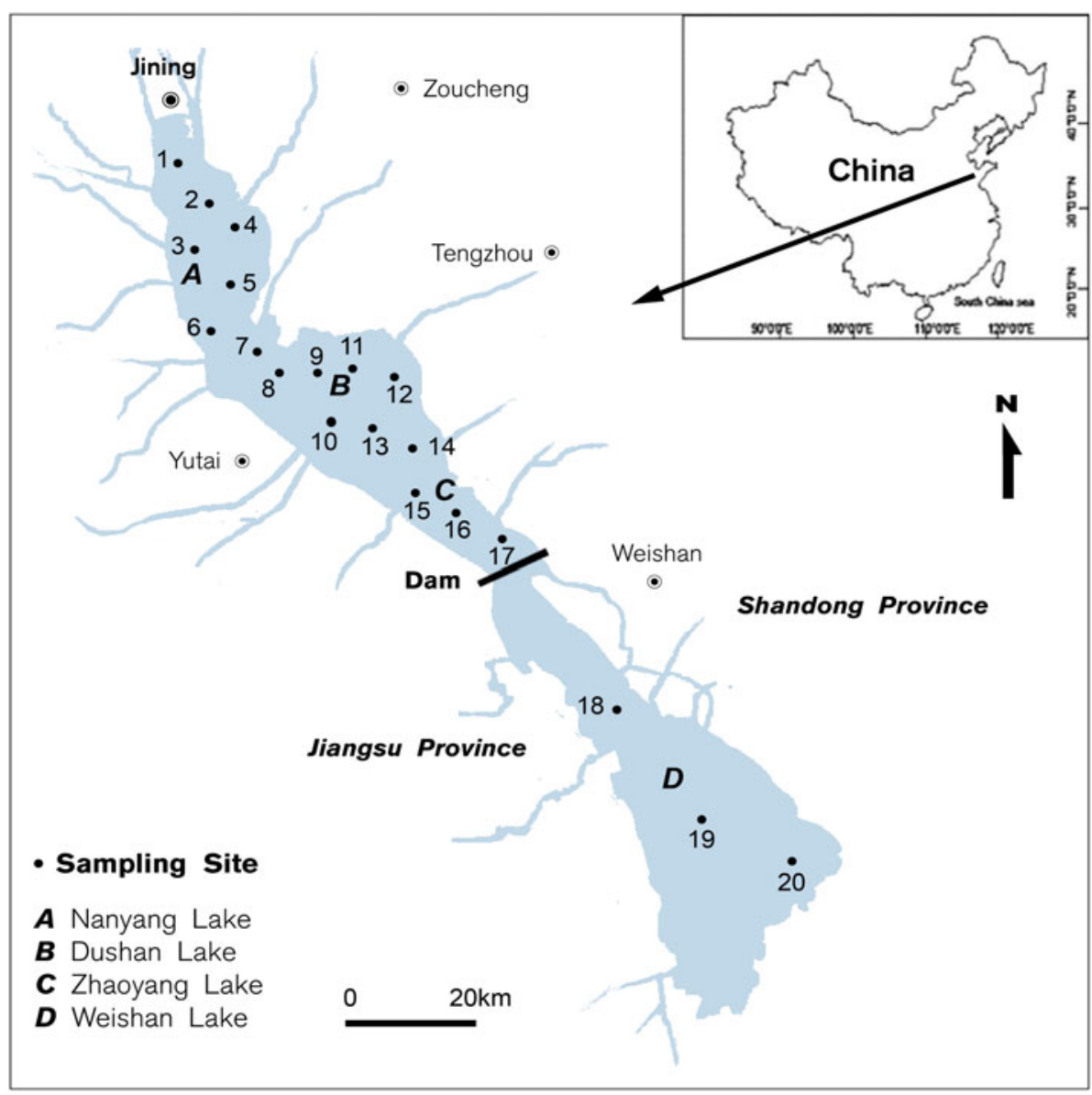

checked by conducting an analysis of a certified reference material (BCR-CRM 277b). The differences between the certified and theoretical values were under the $10 \%$.

Taking into account the anionic behavior of As in the sediment samples, the five-step sequential extraction procedure described from Wenzel et al. (2001) was performed using $1 \mathrm{~g}$ of dry sediment. The extraction procedures were designed to separate specific environmental compartments of As and other trace metals in the sediment samples (Table 1). Non-specifically sorbed As (F1), specifically sorbed As (F2), amorphous and poorly crystalline $\mathrm{Fe}$ and $\mathrm{Al}$ hydrous oxides bound As (F3), and well-formed crystalline $\mathrm{Fe}$ and $\mathrm{Al}$ hydrous oxides bound As (F4) were sequentially and selectively extracted by $\left(\mathrm{NH}_{4}\right)_{2} \mathrm{SO}_{4}$, $\mathrm{NH}_{4} \mathrm{H}_{2} \mathrm{PO}_{4}, \quad \mathrm{NH}_{4}$-oxalate, and $\mathrm{NH}_{4}$-oxalate + ascorbic acid solutions, respectively (Table 1). The content of residual As (F5) was determined by calculating the difference between the TAs content and the sum contents of the reactive fractions described above. The suspensions in each step were centrifuged at $10,000 \mathrm{rpm}$ for $10 \mathrm{~min}$ at room temperature using a Xiang $\mathrm{Yi}$ centrifuge. The supernatants were filtered through a $0.45 \mu \mathrm{m}$ membrane and analyzed by HG-AFS. All reagents were analytical grade. The precision of the sequential extraction method

Table 1 Steps in the selective sequential extraction procedure

\begin{tabular}{llll}
\hline Step & Fraction & Extractant & Experimental conditions \\
\hline 1 & Non-specifically sorbed As & $0.05 \mathrm{M}\left(\mathrm{NH}_{4}\right)_{2} \mathrm{SO}_{4}$ & $4 \mathrm{~h}$ shaking $\left(20^{\circ} \mathrm{C}\right)$ \\
2 & Specifically sorbed As & $0.05 \mathrm{M} \mathrm{NH}_{4} \mathrm{H}_{2} \mathrm{PO}_{4}$ & $16 \mathrm{~h}$ shaking $\left(20^{\circ} \mathrm{C}\right)$ \\
3 & Amorphous and poorly crystalline Fe and & $0.2 \mathrm{M} \mathrm{NH}_{4}$-oxalate $(\mathrm{pH} \mathrm{3.25)}$ wash step: $0.2 \mathrm{M}$ & $4 \mathrm{~h}$ shaking in the dark $\left(20^{\circ} \mathrm{C}\right)$ \\
& $\mathrm{Al}$ hydrous oxides bound As & $\mathrm{NH}_{4}$-oxalate & 10 min shaking $\left(20^{\circ} \mathrm{C}\right)$ \\
4 & Well-crystallized Fe and $\mathrm{Al}$ hydrous oxides & $0.2 \mathrm{M} \mathrm{NH}_{4}$-oxalate $+0.1 \mathrm{M}^{2}$ ascorbic acid $(\mathrm{pH}$ & 30 min shaking in water bath at $96^{\circ} \mathrm{C}$ \\
& bound As & $3.25)$ wash step: $0.2 \mathrm{M} \mathrm{NH}_{4}$-oxalate & 10 min shaking $\left(20^{\circ} \mathrm{C}\right)$ \\
\hline
\end{tabular}


was evaluated by the variation of coefficients $(\mathrm{CV})$ of three replicates from two sediment samples. Average CVs of As were $6.9,6.4,5.8$, and $5.3 \%$ for $\mathrm{F} 1, \mathrm{~F} 2, \mathrm{~F} 3$, and $\mathrm{F} 4$, respectively.

\section{Results and discussion}

General properties of the sediments of Nansi Lake

A selection of general physical and chemical characteristics of the sediments is shown in Table 2 and Fig. 2. The $\mathrm{pH}$ values of the sediments were in the range 7.01-8.21, showing an alkaline character in Nansi Lake. The amount of OM ranged from 4.32 to $14.32 \%$ in the sediments of the Nansi Lake. Mean contents of OM in the sediments of the Nanyang, Dushan, Zhaoyang, and Weishan Lake were 9.57, 11.38, 7.36, and 5.01\%, respectively. As Fig. 2 shown, higher OM content was observed at some sites located in the Nanyang and Dushan Lake, especially in the Dushan Lake. A long-term monitor indicated that annually about 2,900 million tons of untreated domestic sewage and industrial wastewater from the Jining, Zaozhuang, and Heze cities discharged into the Nansi Lake through the 13 main inflow rivers flowing into the Nanyang Lake and Dushan Lake and the contents of chemical oxygen demand (COD) and biological oxygen demand (BOD) in these rivers were higher than the Grade V of the "China surface
Table 2 Properties of the surface sediments of the Nansi Lake
Ave average content, Std standard deviation, $C V$ coefficient of variation, Max the maximum value, $\operatorname{Min}$ the minimum value

\begin{tabular}{|c|c|c|c|c|c|c|c|c|}
\hline Site & $\mathrm{pH}$ & $\mathrm{OM}(\%)$ & $\mathrm{Al}(\%)$ & $\mathrm{Fe}(\%)$ & $\mathrm{Ca}(\%)$ & $\begin{array}{l}\text { Clay }(\%) \\
(<2 \mu \mathrm{m})\end{array}$ & $\begin{array}{l}\text { Silt }(\%) \\
(2-63 \mu \mathrm{m})\end{array}$ & $\begin{array}{l}\text { Sand }(\%) \\
(63-2,000 \mu \mathrm{m})\end{array}$ \\
\hline \multicolumn{9}{|c|}{ Nanyang Lake } \\
\hline 1 & 7.93 & 10.35 & 6.45 & 3.48 & 7.35 & 22.64 & 60.84 & 11.23 \\
\hline 2 & 7.66 & 12.83 & 7.08 & 3.55 & 6.00 & 14.56 & 68.95 & 6.82 \\
\hline 3 & 7.87 & 9.02 & 6.51 & 3.57 & 7.04 & 21.35 & 70.19 & 4.51 \\
\hline 4 & 7.79 & 8.94 & 6.42 & 3.42 & 8.03 & 12.24 & 72.57 & 6.51 \\
\hline 5 & 7.93 & 9.68 & 6.90 & 3.20 & 10.04 & 17.84 & 66.82 & 5.94 \\
\hline 6 & 8.03 & 7.09 & 6.39 & 3.96 & 14.05 & 23.68 & 72.19 & 1.43 \\
\hline 7 & 7.85 & 9.06 & 7.26 & 3.41 & 12.02 & 18.82 & 71.22 & 3.65 \\
\hline Ave & 7.87 & 9.57 & 6.72 & 3.51 & 9.22 & 18.73 & 68.97 & 5.73 \\
\hline \multicolumn{9}{|c|}{ Dushan Lake } \\
\hline 8 & 7.82 & 11.23 & 6.40 & 3.18 & 14.98 & 21.27 & 66.80 & 3.95 \\
\hline 9 & 7.60 & 10.82 & 5.31 & 3.60 & 14.86 & 16.35 & 75.48 & 4.02 \\
\hline 10 & 7.01 & 14.32 & 5.21 & 4.30 & 11.03 & 19.95 & 73.81 & 2.35 \\
\hline 11 & 7.53 & 12.51 & 4.49 & 4.06 & 8.13 & 17.95 & 74.15 & 1.82 \\
\hline 12 & 7.95 & 10.02 & 4.80 & 3.44 & 7.07 & 23.26 & 71.98 & 3.56 \\
\hline 13 & 7.87 & 9.35 & 5.73 & 3.66 & 4.97 & 25.36 & 67.82 & 3.58 \\
\hline Ave & 7.63 & 11.38 & 5.32 & 3.71 & 10.17 & 20.69 & 71.67 & 3.21 \\
\hline \multicolumn{9}{|c|}{ Zhaoyang Lake } \\
\hline 14 & 7.96 & 6.73 & 6.98 & 3.13 & 5.04 & 24.07 & 73.25 & 0.58 \\
\hline 15 & 8.17 & 8.47 & 7.06 & 3.89 & 6.05 & 19.64 & 72.56 & 1.01 \\
\hline 16 & 8.21 & 7.98 & 7.49 & 3.29 & 3.91 & 22.64 & 73.19 & 0.78 \\
\hline 17 & 7.94 & 6.25 & 7.17 & 3.43 & 3.11 & 20.85 & 71.65 & 4.12 \\
\hline Ave & 8.07 & 7.36 & 7.18 & 3.44 & 4.53 & 21.80 & 72.66 & 1.62 \\
\hline \multicolumn{9}{|c|}{ Weishan Lake } \\
\hline 18 & 8.12 & 4.98 & 4.46 & 3.28 & 2.00 & 19.68 & 70.34 & 7.53 \\
\hline 19 & 8.15 & 5.72 & 5.02 & 3.01 & 2.50 & 15.35 & 73.65 & 6.25 \\
\hline 20 & 8.02 & 4.32 & 6.30 & 2.82 & 4.05 & 17.25 & 73.58 & 3.08 \\
\hline Ave & 8.10 & 5.01 & 5.26 & 3.04 & 2.85 & 17.43 & 72.52 & 5.62 \\
\hline \multicolumn{9}{|c|}{ Nansi Lake } \\
\hline Ave & 7.87 & 8.98 & 6.17 & 3.48 & 7.61 & 19.74 & 71.05 & 4.14 \\
\hline Std & 0.27 & 2.65 & 0.97 & 0.36 & 4.03 & 3.47 & 3.42 & 2.66 \\
\hline CV\% & 3.45 & 29.51 & 15.73 & 10.42 & 53.01 & 17.59 & 4.82 & 64.24 \\
\hline Max & 8.21 & 14.32 & 7.49 & 4.30 & 14.98 & 25.36 & 75.48 & 11.23 \\
\hline Min & 7.01 & 4.32 & 4.46 & 2.82 & 2.00 & 12.24 & 60.84 & 0.58 \\
\hline
\end{tabular}




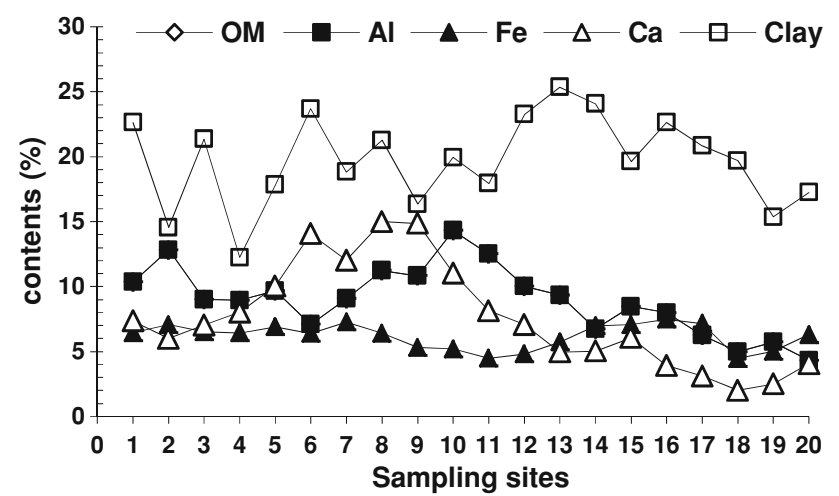

Fig. 2 Contents of $\mathrm{OM}, \mathrm{Al}, \mathrm{Fe}, \mathrm{Ca}$, and Clay in the surface sediments of the Nansi Lake

water quality standard" (Zhang et al. 1999). Under natural conditions, inorganic, and organic materials are carried and deposited by water from the upper lake to the lower lake. Therefore, the content of OM was higher in the upper lake sediments than that of the lower lake sediments. In addition, faster development of aquaculture as well as richness in aquatic plants in the Dushan Lake than other lakes might also contribute to high OM contents in the Dushan Lake sediments (Qu et al. 2001).

The content of $\mathrm{Ca}$ in the sediments of the Nansi Lake was in the range $2.00-15.43 \%$. From Fig. 2, it was observed that the $\mathrm{Ca}$ contents of the sediments at the sampling sites 4-11 were higher than that of other sites. The average content of $\mathrm{Ca}$ of the sediments was the highest in the Dushan Lake. The limestone is widespread in the eastern mountain of the Dushan Lake, which might contribute to the high content of $\mathrm{Ca}$ in the sediments nearby the mountain (Lang 1983). The amounts of $\mathrm{Al}$ and $\mathrm{Fe}$ in the sediments of the Nansi Lake ranged from 4.10 to $7.46 \%$ and 2.74 to $4.13 \%$, respectively (Table 2 ). Mean contents of $\mathrm{Al}$ and $\mathrm{Fe}$ were 6.17 and 3.55, respectively. As shown in Fig. 2, for all the sediments of the Nansi Lake, the $\mathrm{Al}$ and Fe contents had no big change. The average contents of clay in the sediments of the Nanyang Lake, Dushan Lake, Zhaoyang Lake, and Weishan Lake were 18.73, 20.69, 21.80 , and $17.43 \%$, respectively, had no big difference among four lakes, though it fluctuated at some sampling sites (Fig. 2).

Total As in the surface sediments of Nansi Lake

The TAs content of the sediments ranged from $8.27 \mathrm{mg} / \mathrm{kg}$ at site $20-21.75 \mathrm{mg} / \mathrm{kg}$ at site 10 , with a mean value of $13.45 \mathrm{mg} / \mathrm{kg}$ (Table 3). Mean content of As in the Nanyang, Dushan, Zhaoyang, and Weishan Lake was 13.54, $16.86,11.28$, and $9.34 \mathrm{mg} / \mathrm{kg}$, respectively. So the average content of As of the sediment samples was much higher for the Nanyang Lake and Dushan Lake than that for the
Zhaoyang Lake and Weishan Lake. The highest concentration of As was observed at site 10 in Dushan Lake, and the lowest concentration of As was found at site 20 in Weishan Lake. It was observed that the Nansi Lake was formed by bedload from flooding of the Yellow River (Lang 1983), so the average content of As in the main river sediments of Yellow River was used as the background content in the present study and it was $7.50 \mathrm{mg} / \mathrm{kg}$ (Zhao and Yan 1992). The mean content of As in worldwide river sediments is $5.0 \mathrm{mg} / \mathrm{kg}$ (Martin and Whitfield 1983). Hence, the surface sediments of the Nansi Lake contained much higher As than the world wide river sediments and the main river sediments of Yellow River. In addition, the concentration of As of all sediment samples in the Nansi Lake was also lower than the threshold values of the Chinese soil environmental quality criteria $(20 \mathrm{mg} / \mathrm{kg})$ (National Standard of PR China 1995) and the control standards for pollutants in sludges from agricultural use $(75 \mathrm{mg} / \mathrm{kg}$ ) (National Standard of PR China 1984), respectively.

Industries such as manufacture of pharmacy, fertilizer, textile, and printing developed extremely quickly in the Jining, Zaozhuang, and Heze cities, which might result in the emission of As pollutants. It was reported that $9.34 \times 10^{5}, 7.41 \times 10^{5}$, and $1.98 \times 10^{5}$ tons of untreated industrial wastewater were discharged into the Nansi Lake from Jining, Zaozhuang, and Heze cities annually, respectively (Zhang et al. 1999). A long-term monitor indicated that 13 inflow rivers were all polluted by heavy metals due to various industries (Liu et al. 2007). Thus, industrial effluents were one important reason that resulted in the relatively high As content in the sediments of the Nansi Lake, especially in the upper lake.

The coal resources are very rich in the region around the Nansi Lake. There are some big coal-fired power plants such as Jining, Zoucheng, Jiaxiang, and Liyan power plants nearby the Nansi Lake, and their total installed capacity is more than 10 million kilowatts (Feng et al. 1999). Previous research indicated that the average amount of As was $2.5 \mathrm{mg} / \mathrm{kg}$ in the coal of the mining districts nearby the Nansi Lake (Liu et al. 2002), and more than $90 \%$ of them was discharged into the environment (Feng et al. 1999). So, the mining waste might be one of important pollution sources of As for the sediments of the Nansi Lake.

In the Nansi Lake, water flows from the upper lake to the lower lake. The sediments of the upper lake are affected first by the effluents. After aggradation and decontamination in the upper lake, sediments in the lower lake are at a corresponding low-grade contamination level. So the TAs content of the sediments in the upper lake is higher than that of the lower lake.

In this study, the content of TAs was positively correlated to the $\mathrm{OM}$ and $\mathrm{Fe}$ contents, but not correlated to the 
Table 3 The basic statistical parameters of various As chemical forms in the surface sediments of the Nansi Lake

\begin{tabular}{|c|c|c|c|c|c|c|c|c|c|c|c|}
\hline \multirow[t]{2}{*}{ Site } & \multicolumn{6}{|c|}{ As concentrations $(\mathrm{mg} / \mathrm{kg})$} & \multicolumn{5}{|c|}{ As proportions $(\%)$} \\
\hline & $\mathrm{F} 1$ & $\mathrm{~F} 2$ & $\mathrm{~F} 3$ & $\mathrm{~F} 4$ & F5 & TAs & $\mathrm{F} 1$ & $\mathrm{~F} 2$ & $\mathrm{~F} 3$ & $\mathrm{~F} 4$ & F5 \\
\hline \multicolumn{12}{|c|}{ Nanyang Lake } \\
\hline 1 & 0.07 & 1.64 & 5.13 & 3.53 & 2.00 & 12.37 & 0.55 & 13.28 & 41.45 & 28.52 & 16.20 \\
\hline 2 & 0.15 & 2.53 & 6.48 & 3.12 & 2.72 & 14.99 & 0.97 & 16.87 & 43.23 & 20.81 & 18.12 \\
\hline 3 & 0.06 & 1.75 & 5.20 & 3.33 & 3.23 & 13.58 & 0.46 & 12.92 & 38.29 & 24.55 & 23.79 \\
\hline 4 & 0.07 & 2.04 & 6.14 & 2.98 & 1.73 & 12.97 & 0.57 & 15.73 & 47.35 & 23.00 & 13.34 \\
\hline 5 & 0.11 & 1.11 & 4.24 & 3.39 & 1.17 & 10.01 & 1.05 & 11.08 & 42.38 & 33.84 & 11.65 \\
\hline 6 & 0.08 & 1.61 & 5.63 & 4.97 & 4.70 & 16.99 & 0.46 & 9.51 & 33.16 & 29.24 & 27.63 \\
\hline 7 & 0.04 & 1.56 & 5.58 & 3.24 & 3.44 & 13.86 & 0.31 & 11.23 & 40.25 & 23.37 & 24.85 \\
\hline Ave & 0.08 & 1.75 & 5.49 & 3.51 & 2.71 & 13.54 & 0.62 & 12.95 & 40.87 & 26.19 & 19.37 \\
\hline \multicolumn{12}{|c|}{ Dushan Lake } \\
\hline 8 & 0.10 & 1.42 & 5.60 & 3.78 & 3.48 & 14.38 & 0.68 & 9.87 & 38.92 & 26.31 & 24.22 \\
\hline 9 & 0.13 & 2.34 & 6.51 & 4.20 & 2.17 & 15.35 & 0.85 & 15.23 & 42.43 & 27.33 & 14.15 \\
\hline 10 & 0.09 & 1.98 & 9.50 & 6.89 & 3.30 & 21.75 & 0.44 & 9.09 & 43.66 & 31.66 & 15.16 \\
\hline 11 & 0.13 & 2.90 & 7.58 & 4.54 & 3.78 & 18.92 & 0.67 & 15.33 & 40.04 & 23.98 & 19.99 \\
\hline 12 & 0.06 & 2.92 & 6.47 & 3.79 & 3.54 & 16.79 & 0.36 & 17.38 & 38.56 & 22.58 & 21.11 \\
\hline 13 & 0.11 & 1.54 & 5.17 & 3.93 & 3.19 & 13.95 & 0.78 & 11.06 & 37.08 & 28.20 & 22.88 \\
\hline Ave & 0.10 & 2.18 & 6.80 & 4.52 & 3.25 & 16.86 & 0.63 & 12.99 & 40.12 & 26.68 & 19.59 \\
\hline \multicolumn{12}{|c|}{ Zhaoyang Lake } \\
\hline 14 & 0.08 & 1.21 & 4.09 & 2.50 & 2.66 & 10.54 & 0.77 & 11.49 & 38.79 & 23.74 & 25.21 \\
\hline 15 & 0.07 & 1.28 & 5.68 & 3.24 & 1.39 & 11.66 & 0.61 & 11.01 & 48.71 & 27.76 & 11.91 \\
\hline 16 & 0.05 & 1.72 & 3.83 & 2.52 & 1.86 & 9.97 & 0.48 & 17.22 & 38.40 & 25.24 & 18.65 \\
\hline 17 & 0.04 & 1.29 & 6.57 & 2.58 & 2.47 & 12.95 & 0.34 & 9.98 & 50.70 & 19.94 & 19.04 \\
\hline Ave & 0.06 & 1.38 & 5.04 & 2.71 & 2.09 & 11.28 & 0.55 & 12.42 & 44.15 & 24.17 & 18.70 \\
\hline \multicolumn{12}{|c|}{ Weishan Lake } \\
\hline 18 & 0.12 & 1.58 & 4.26 & 2.88 & 1.43 & 10.27 & 1.21 & 15.39 & 41.51 & 28.02 & 13.88 \\
\hline 19 & 0.06 & 0.93 & 3.70 & 2.45 & 2.35 & 9.49 & 0.62 & 9.79 & 38.98 & 25.82 & 24.80 \\
\hline 20 & 0.05 & 1.13 & 3.51 & 2.21 & 1.37 & 8.27 & 0.64 & 13.71 & 42.40 & 26.68 & 16.57 \\
\hline Ave & 0.08 & 1.21 & 3.82 & 2.51 & 1.72 & 9.34 & 0.82 & 12.96 & 40.96 & 26.84 & 18.41 \\
\hline \multicolumn{12}{|c|}{ Nansi Lake } \\
\hline Ave & 0.08 & 1.72 & 5.54 & 3.50 & 2.60 & 13.45 & 0.64 & 12.86 & 41.31 & 26.03 & 19.16 \\
\hline Std & 0.03 & 0.57 & 1.46 & 1.08 & 0.97 & 3.40 & 0.24 & 2.80 & 4.12 & 3.46 & 4.96 \\
\hline CV \% & 38.91 & 33.17 & 26.26 & 30.80 & 37.18 & 25.27 & 37.66 & 21.80 & 9.96 & 13.30 & 25.87 \\
\hline Max & 0.15 & 2.92 & 9.50 & 6.89 & 4.70 & 21.75 & 1.21 & 17.38 & 50.70 & 33.84 & 27.63 \\
\hline Min & 0.04 & 0.93 & 3.51 & 2.21 & 1.17 & 8.27 & 0.31 & 9.09 & 33.16 & 19.94 & 11.65 \\
\hline
\end{tabular}

$\mathrm{Al}$ content in the sediments of Nansi Lake (Fig. 3). The occurrence of high concentration of As with increasing OM content is possibly due to the formation of organarsenic complexes and the humic substances in the sediment and soil were known to be adsorbents for As (Pikaray et al. 2005). Since, the TAs content was positively correlated to the OM content, so organic matter plays a significant role in controlling As transport in the sediments of the Nansi Lake. Moreover, the As in the OM fraction was stable in the sediments because most of it cannot be exchanged by phosphate anions (Filgueiras et al. 2002; Smedley and Kinniburgh 2002). The regressions of the As content vs. the $\mathrm{Fe}$ and $\mathrm{Al}$ contents were discussed in the following text.

Chemical partitioning of As in the surface sediments of Nansi Lake

The As content in the F1, F2, F3, F4, and F5 fractions ranged from 0.04 to $0.15,0.93$ to $2.92,3.51$ to $9.50,2.21$ to 6.89 , and 1.17 to $4.70 \mathrm{mg} / \mathrm{kg}$, respectively, with average contents of $0.08,1.72,5.54,3.50$, and $2.60 \mathrm{mg} / \mathrm{kg}$. The proportions of As in F1, F2, F3, F4, and F5 were 0.64, $12.86,41.32,26.03$, and $19.16 \%$, respectively (Table 3; 

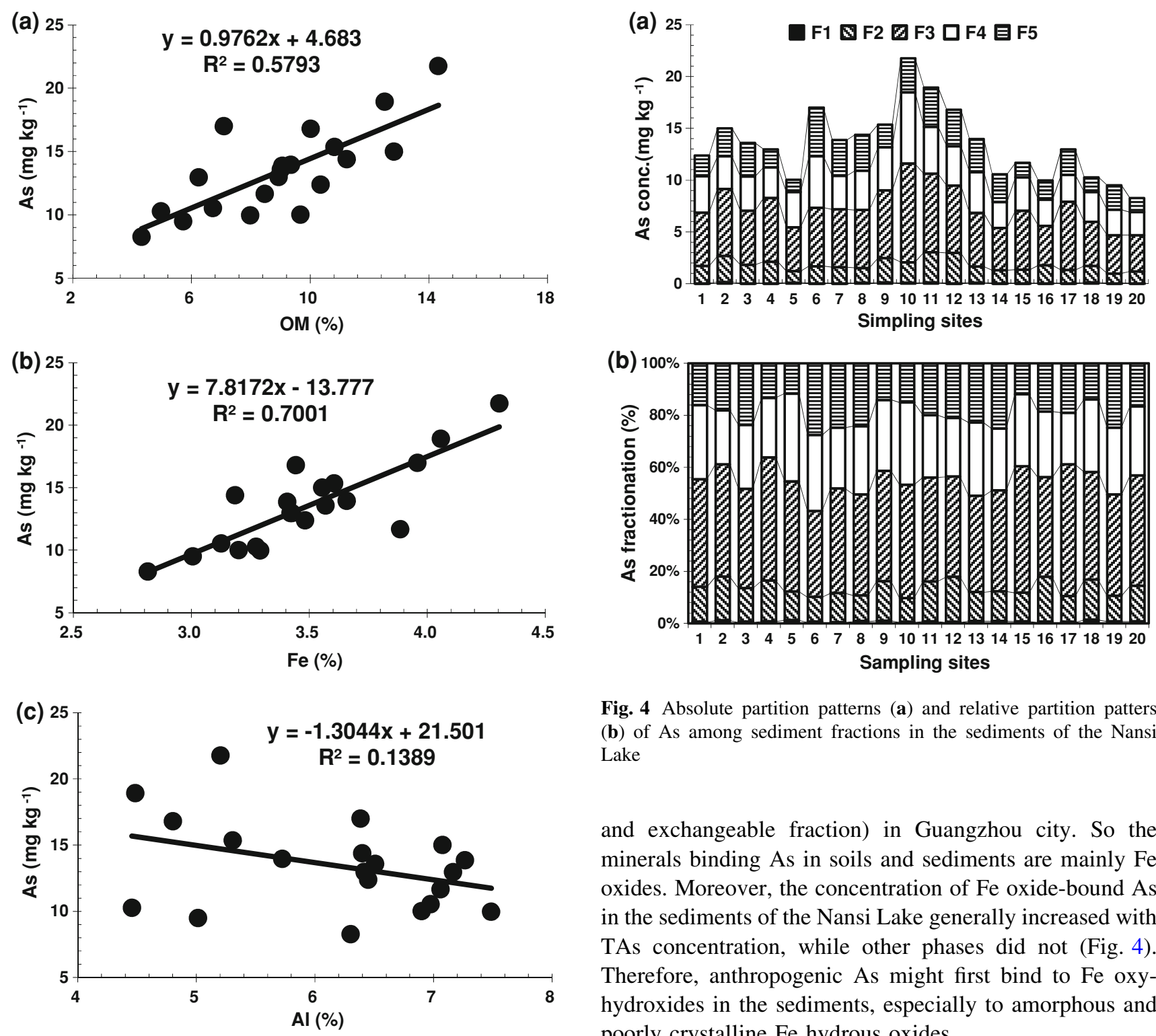

Fig. 4 Absolute partition patterns (a) and relative partition patters (b) of As among sediment fractions in the sediments of the Nansi Lake

and exchangeable fraction) in Guangzhou city. So the minerals binding As in soils and sediments are mainly $\mathrm{Fe}$ oxides. Moreover, the concentration of Fe oxide-bound As in the sediments of the Nansi Lake generally increased with TAs concentration, while other phases did not (Fig. 4). Therefore, anthropogenic As might first bind to Fe oxyhydroxides in the sediments, especially to amorphous and poorly crystalline Fe hydrous oxides.

It is well known that the major minerals binding As in

Fig. 3 Correlations between the content of As and the content of $\mathrm{OM}, \mathrm{Fe}$, and $\mathrm{Al}$ in the surface sediments of the Nansi Lake: a As versus $\mathrm{OM}$, b As versus $\mathrm{Fe}$, c As versus $\mathrm{Al}$

Fig. 4). The average As content in each fraction was in the order of F3 $>$ F4 $>$ F5 $>$ F2 $>$ F1. The sum of F3, F4, and F5 fractions comprised over $85 \%$ of the TAs content. Iron oxide-bound As comprised more than $65 \%$ of the TAs. Wenzel et al. (2001) found that average percentages of As in the F1, F2, F3, F4, and F5 fractions in the 20 soil samples were $0.3,9.0,39.8,29.6$, and $19.5 \%$, respectively. Haque et al. (2008) observed that the As in the F1, F2, F3, F4, and F5 fractions comprised 1.1, 12.3, 29.0, 34.6, and $23.0 \%$ of TAs in the sediments of Aquia aquifer, MA, USA, when the same extraction procedure as in this study was used. Feng et al. (2009) found that about $74 \%$ of As in the air-borne fine particle was in bioavailable form (soluble sediments were $\mathrm{Fe}$ oxides due to their greater abundance, specific surface area, and stronger binding affinity. The binding of As with $\mathrm{Fe}$ oxides was either via co-precipitation that incorporates As into the mineral or amorphous phase structures, or via adsorption onto surface sites (Fuller et al. 1993), or via penetration into the lattice (Filgueiras et al. 2002). The residual phase As is relatively stable compared to the $\mathrm{pH}$ and redox sensitive $\mathrm{Fe}, \mathrm{Mn}$, or $\mathrm{Al}$ oxyhydroxides bound As, which is thus not expected to be one source of As in the watercolumn system. Therefore, the relatively high content of the residual fraction might be beneficial from an environmental risk perspective.

Regressions of the As concentration in the F3 fraction (F3-As) versus $\mathrm{Al}$ and F3-As versus $\mathrm{Fe}$ were shown in Fig. 5, and the results revealed that the F3-As was positively correlated to the Fe content in the sediments of the 

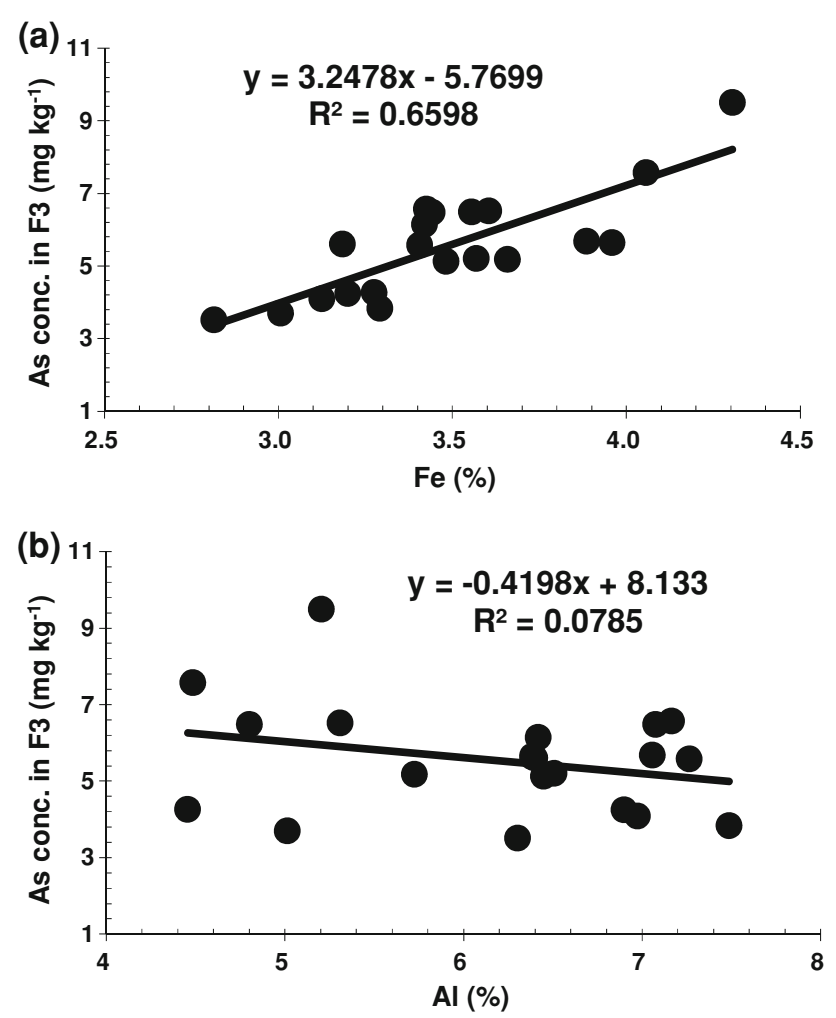

Fig. 5 Correlations between As concentration in the F3 fraction and the content of $\mathrm{Fe}$ and $\mathrm{Al}$ in the sediments of the Nansi Lake: a As conc. in $\mathrm{F} 3$ versus $\mathrm{Fe}$, b As conc. in $\mathrm{F} 3$ versus $\mathrm{Al}$

Nansi Lake, while the F3-As was not correlated to the Al content.

From Fig. 5, it may be observed that $\mathrm{Fe}$ and $\mathrm{Al}$ are the main metals of the natural As-binding phases and strongly correlated to the fine-grained sediment fraction as well as As. Fe and $\mathrm{Al}$ oxides have been often used as sorbents to remove As from water and wastewater. Generally, the determination coefficients of As versus Fe regressions were higher than those of As versus Al (Table 4). Arsenic was negatively correlated to $\mathrm{Al}$ in the sediments of Western North Sea (Whalley et al. 1999) and the Nansi Lake. The regression slopes of As versus Fe generally ranged from 1.90 to 15.4 , while the slope for the sediments of the Nansi Lake was 7.82. High regression slopes of As versus Fe usually showed high anthropogenic input of As into sediments. The study areas mentioned in Table 4 were contaminated by heavy metals to different degree. For example, the Dexing area studied by Teng et al. (2009) is a famous foundation of nonferrous mineral resources in China, and there are some giant deposits such as $\mathrm{Cu}-\mathrm{Mo}$, $\mathrm{Au}-\mathrm{Ag}$, and $\mathrm{Ag}-\mathrm{Pb}-\mathrm{Zn}$ deposits in this area. The sediments in the Humbr Estuary and Western North Sea were contaminated heavily by $\mathrm{Fe}$ waste and As (Whalley et al. 1999). The other areas mentioned in Table 4 were about the sediments pollution survey of costal of the United States (Daskalakis and O'Connor 1995; Summer et al. 1996; Schiff and Weisberg 1999).

Some previous detailed mineralogical studies demonstrated the large As sorption capacity of hydrous ferric oxide (HFO), which showed that the molar ratios of As to Fe were 0.7 and 0.25 for coprecipitation and sorption experiments, respectively (Fuller et al. 1993; Raven et al. 1998). Natural As-rich HFO precipitates can attain sorption densities of up to 0.2 mole-As/mole-Fe (Pichler et al. 1999). However, Belzile and Tessier (1990) reported that average molar ratios of $\mathrm{As}$ to $\mathrm{Fe}$ for the recent lacustrine sediments were in the range $3.80 \times 10^{-5}$ to $2.12 \times 10^{-2}$. Synthesized Schwermannite had a maximal molar ratio of $2.0 \times 10^{-2}$ (Asta et al. 2009). The maximal molar ratios of As to Fe for natural hematite, magnetite, and goethite were $2.83 \times 10^{-4}, 2.21 \times 10^{-4}$, and $4.45 \times 10^{-4}$ for As (III), respectively; while they were $8.82 \times 10^{-4}, 2.71 \times 10^{-4}$, and $5.34 \times 10^{-4}$ for As (V) (Giménez et al. 2007). The

Table 4 Regression equations of As versus $\mathrm{Fe}$ or $\mathrm{Al}$ in unit of $\mathrm{mg} / \mathrm{kg}$ in the sediments at various sites

\begin{tabular}{|c|c|c|c|c|c|}
\hline Site & Regression equation & $R^{2}$ & $P$ & $n$ & References \\
\hline \multirow[t]{2}{*}{ East and Gulf of Mexico } & {$[\mathrm{As}]=3.25 \times 10^{-4}[\mathrm{Fe}]+0.59$} & 0.680 & $<0.05$ & 360 & Daskalakis and O'Connor (1995) \\
\hline & {$[\mathrm{As}]=1.68 \times 10^{-4}[\mathrm{Al}]-0.54$} & 0.520 & $<0.05$ & 360 & Daskalakis and O'Connor (1995) \\
\hline Southern California coastal shelf & {$[\mathrm{As}]=1.90 \times 10^{-4}[\mathrm{Fe}]+1.49$} & 0.750 & $<0.0001$ & 110 & Schiff and Weisberg (1999) \\
\hline Gulf of Mexico & {$[\mathrm{As}]=0.91 \times 10^{-4}[\mathrm{Al}]+1.19$} & 0.830 & $<0.001$ & 103 & Summer et al. (1996) \\
\hline \multirow[t]{2}{*}{ Humber Estuary } & {$[\mathrm{As}]=8.09 \times 10^{-4}[\mathrm{Fe}]+6.81$} & 0.747 & $<0.001$ & 16 & Whalley et al. (1999) \\
\hline & {$[\mathrm{As}]=5.32 \times 10^{-4}[\mathrm{Al}]+9.00$} & 0.750 & $<0.001$ & 16 & Whalley et al. (1999) \\
\hline \multirow[t]{2}{*}{ Western North Sea } & {$[\mathrm{As}]=15.40 \times 10^{-4}[\mathrm{Fe}]-4.12$} & 0.541 & $<0.1$ & 195 & Whalley et al. (1999) \\
\hline & {$[\mathrm{As}]=-1.19 \times 10^{-4}[\mathrm{Al}]+16.78$} & 0.003 & - & 195 & Whalley et al. (1999) \\
\hline \multirow[t]{2}{*}{ Dogger Bank } & {$[\mathrm{As}]=7.31 \times 10^{-4}[\mathrm{Fe}]-0.06$} & 0.406 & $<0.001$ & 258 & Whalley et al. (1999) \\
\hline & {$[\mathrm{As}]=6.09 \times 10^{-4}[\mathrm{Al}]-3.23$} & 0.203 & $<0.001$ & 258 & Whalley et al. (1999) \\
\hline Dexing area & {$[\mathrm{As}]=2.16 \times 10^{-4}[\mathrm{Al}]+2.42$} & 0.317 & $<0.01$ & 326 & Teng et al. (2009) \\
\hline \multirow[t]{2}{*}{ Nansi Lake } & {$[\mathrm{As}]=7.82 \times 10^{-4}[\mathrm{Fe}]-13.78$} & 0.700 & $<0.0001$ & 20 & This study \\
\hline & {$[\mathrm{As}]=-1.30 \times 10^{-4}[\mathrm{Al}]+21.50$} & 0.139 & $<0.01$ & 20 & This study \\
\hline
\end{tabular}


molar ratios of As to $\mathrm{Fe}$ in the surface sediments of the Nansi Lake were in the range $2.19 \times 10^{-4}$ to $3.64 \times 10^{-4}$, with an average of $2.85 \times 10^{-4}$, indicating that there is still substantial potential for the adsorption of As.

Potential ecosystem risk assessment

Previous researches used geoaccumulation index, enrichment factor, potential ecological risk index, pollution load index, and sediment quality guidelines (SQGs) to assess the heavy metal and metalloid pollution of sediments (Karbassi et al. 2006; Mohiuddin et al. 2010; Sekabira et al. 2010). In order to quantitatively assess As risk in the sediments of the Nansi Lake, the As levels in the sediment were compared with the SQGs of threshold effect concentration (TEC) and probable effect concentration (PEC) (MacDonald et al. 1996; Swartz 1999), threshold effect level (TEL) and probable effect level (PEL) (Smith et al. 1996). The TEC for As is $9.79 \mathrm{mg} / \mathrm{kg}$ and intends to identify contaminant concentration below which harmful effects on sediment-dwelling organisms were not expected (MacDonald et al. 1996; Swartz 1999). The PEC for As is $33.0 \mathrm{mg} / \mathrm{kg}$ and intends to identify contaminant concentration above which harmful effects on sediment-dwelling organisms were expected to occur frequently (MacDonald et al. 1996; Swartz 1999). The TEL for As is $5.9 \mathrm{mg} / \mathrm{kg}$, representing the concentration below which adverse effects would rarely occur (Smith et al. 1996). The PEL for As is $17 \mathrm{mg} / \mathrm{kg}$ and represents the concentration above which adverse effects would frequently occur (Smith et al. 1996). The total concentrations of As ranged from 8.27 to $21.75 \mathrm{mg} / \mathrm{kg}$ (Table 3) in the sediments of the Nansi Lake, which were usually higher than TEC and TEL but lower than PEC and PEL, thus indicating adverse effects or toxicity to the aquatic organisms, caused by As in the sediments of the Nansi Lake, will likely occur at these levels of As contamination. Therefore, it is necessary to remediate the sediments of the Nansi Lake to reduce and remove potential risk of As in the sediments.

\section{Conclusion}

The TAs content in the surface sediments of the Nansi Lake was in the range $8.27-21.75 \mathrm{mg} / \mathrm{kg}$, with an average of $13.45 \mathrm{mg} / \mathrm{kg}$. This content was higher than in the TEL, and thus, it is likely that adverse effects caused by As might occur in the sediments of the Nansi Lake. The arsenic was mostly associated with Fe oxides, followed by association with the residual fraction. The F3-As contents were correlated to the $\mathrm{Fe}$ contents in the sediments. The TAs content was positively correlated to the $\mathrm{Fe}$ and $\mathrm{OM}$ contents in the sediments. The molar ratio of As to Fe was lower than the maximal molar ratios of As to $\mathrm{Fe}$ for natural hematite, magnetite, and goethite. Generally, the sediments of the Nansi Lake were contaminated by As and needs to be remediated to maintain aquatic ecosystem health.

Acknowledgments Financial supports to Wang, S. L. and Lin, C. Y. by the National Natural Science Foundation of China (40971058) and Program for Changjiang Scholars and Innovative Research Team in University (No.IRT0809) are acknowledged.

\section{References}

Asta MP, Cama J, Martínez M, Giménez J (2009) Arsenic removal by goethite and jarosite in acidic conditions and its environmental implications. J Hazard Mater 171(1-3):965-972

Bao SD (1999) Measurement of organic matter content in soil. In: Bao SD, Jiang RF, Yang CG (eds) Analysis of agri-chemistry in soil (3rd edn) (in Chinese). Chinese Agricultural Science and Technology Press, Beijing, pp 34-35

Belzile N, Tessier A (1990) Interaction between arsenic and iron oxyhydroxides in lacustrine sediments. Geochim Cosmochim Acta 54(1):103-109

Blute NK, Jay JA, Swartz CH, Brabander DJ, Hemond HF (2009) Aqueous and solid phase arsenic speciation in the sediments of a contaminated wetland and riverbed. Appl Geochem 24(2): 346-358

Chilvers DC, Peterson PJ (1987) Global cycling of arsenic. In: Hutchinson TC, Meema KM (eds) Lead, mercury, cadmium and arsenic in the environment. John Wiley \& Sons, Chichester, p 279

Daskalakis KD, O’Connor TP (1995) Normalization and elemental sediment contamination in the coastal United States. Environ Sci Technol 29(2):470-477

Feng XB, Hong B, Ni JY, Hong YT (1999) Chemical mobility of potentially toxic trace elements in coal at surface conditions (in Chinese with English abstract). Acta Sci Circumst 19(4): 433-437

Feng XD, Dang Z, Huang WL, Yang C (2009) Chemical speciation of fine particle bound trace metals. Int $J$ Environ Sci Technol 6(3):337-346

Filgueiras AV, Lavilla I, Bendicho C (2002) Chemical sequential extraction for metal partitioning in environmental solid samples. J Environ Monitor 4(6):823-857

Fuller CC, Davis JA, Waychunas GA (1993) Surface chemistry of ferrihydrite: Part 2 Kinetics of arsenate adsorption and coprecipitation. Geochim Cosmochim Acta 57(10):2271-2282

Giménez J, Martínez M, Pablo J, Rovira M, Duro L (2007) Arsenic sorption onto natural hematite, magnetite, and goethite. J Hazard Mater 141(3):575-580

Gruebel KA, Leckie JO, Davis JA (1988) The feasibility of using sequential extraction techniques for arsenic and selenium in soils and sediments. Soil Sci Soc Am J 52(2):390-397

Haque S, Ji JF, Johannesson KH (2008) Evaluating mobilization and transport of arsenic in sediments and groundwaters of Aquia aquifer, Maryland, USA. J Contam Hydrol 99(1-4):68-84

Karbassi AR, Bayati I, Moattar F (2006) Origin and chemical partitioning of heavy metals in riverbed sediments. Int J Environ Sci Technol 3(1):35-42

Keon NE, Swartz CH, Brabander DJ, Harvey C, Hemond HF (2001) Validation of an arsenic sequential extraction method for evaluating mobility in sediments. Environ Sci Technol 35(13): 2778-2784 
Lang LR (1983) Study on formation of Nansi Lake (in Chinese with English abstract). Trans Oceanol Limnol 4(1):31-38

Liu EF, Shen J, Yang LY, Zhu YX, Sun QY, Wang JJ (2007) Chemical fractionation and pollution characteristics of heavy metals in the sediment of Nansi Lake and its main inflow rivers (in Chinese with English abstract). China Environ Sci 28(6): 1377-1383

Liu GJ, Yang P, Peng ZC, Wang GL, Cao ZH (2002) Occurrence of trace elements in coal of Yanzhou Mining District (in Chinese with English abstract). Geochimica 31(1):85-90

MacDonald DD, Carr RS, Calder FD, Long ER, Ingersoll CG (1996) Development and evaluation of sediment quality guidelines for Florida coastal waters. Ecotoxicology 5(4):253-278

Martin JM, Whitfield M (1983) The significance of the river input of chemical elements to the ocean. In: Wong CS, Boyle E, Bruland KW, Burton JD, Goldberg ED (eds) Trace metals in seawater. Plenum Press, New York, p 265

Mohiuddin KM, Zakir HM, Otomo K, Sharmin S, Shikazono N (2010) Geochemical distribution of trace metal pollutants in water and sediments of downstream of an urban river. Int $\mathbf{J}$ Environ Sci Technol 7(1):17-28

National Standard of PR China (1984) Control standards for pollutants in sludges from agricultural use (GB 4284-84). Standards Press of China, Beijing (in Chinese)

National Standard of PR China (1995) Soil environmental quality (GB 15618-1995). Standards Press of China, Beijing (in Chinese)

Phiri O, Mumba P, Moyo BHZ, Kadewa W (2005) Assessment of the impact of industrial effluents on water quality of receiving rivers in urban areas of Malawi. Int J Environ Sci Technol 2(3): $237-244$

Pichler T, Veizer J, Hall GEM (1999) Natural input of arsenic into a coral-reef ecosystem by hydrothermal fluids and its removal by Fe (III) oxyhydroxides. Environ Sci Technol 33(9):1373-1378

Pikaray S, Banerjee S, Mukherji S (2005) Sorption of arsenic onto Vindhyan shales: role of pyrite and organic carbon. Curr Sci 88(10):1580-1585

Qu WC, Dickman M, Wang SM (2001) Mutivariate analysis of heavy metal and nutrient concentrations in sediments of Taihu Lake, China. Hydrobiologica 450(1-3):83-89
Raven KP, Jain A, Loeppert RH (1998) Arsenite and arsenate adsorption on ferrihydrite: kinetics, equilibrium and adsorption envelopes. Environ Sci Technol 32(3):344-349

Schiff KC, Weisberg SB (1999) Iron as a reference element for determining trace metal enrichment in Southern California coastal shelf sediments. Mar Environ Res 48(2):161-176

Sekabira K, Oryem Origa H, Basamba TA, Mutumba G, Kakudidi E (2010) Assessment of heavy metal pollution in the urban stream sediments and its tributaries. Int J Environ Sci Technol 7(3): 435-446

Smedley PL, Kinniburgh DG (2002) A review of the source, behaviour and distribution of arsenic in natural waters. Appl Geochem 17(5):517-568

Smith SL, MacDonald DD, Keenleyside KA, Ingersoll CG, Field J (1996) A preliminary evaluation of sediment quality assessment values for freshwater ecosystems. J Great Lakes Res 22(3): $624-638$

Summer JK, Wade TL, Engle VD (1996) Normalization of metal concentrations in estuarine sediments from the Gulf of Mexico. Estuar Coast 19(3):581-594

Swartz RC (1999) Consensus sediment quality guidelines for polycyclic aromatic hydrocarbon mixtures. Environ Toxicol Chem 18(4):780-787

Teng Y, Ni S, Wang L, Niu L (2009) Geochemical baseline of trace elements in the sediment in Dexing area, South China. Environ Geol 57(7):1649-1660

Wenzel WW, Kirchbaumer N, Prohaska T, Stingeder G, Lombi E, Adriano DC (2001) Arsenic fractionation in soils using an improved sequential extraction procedure. Anal Chim Acta 436(2):309-323

Whalley C, Rowlatt S, Bennett M, Lovell D (1999) Total arsenic in sediments from the western North Sea and Humber Estuary. Mar Pollut Bull 38(5):394-400

Zhang ZL, Sun QY, Peng LM, Niu ZG, Wu AM (1999) Water environment problems in the Nansi Lake area (in Chinese with English abstract). J Lake Sci 11(1):86-90

Zhao YY, Yan MC (1992) Comparison of chemical elements abundance of Yellow River, Yangtze River and shallow sea in China (in Chinese with English abstract). Chin Sci Bull 37(13): 1202-1204 